\title{
MRI of the Pelvic Floor and MR Defecography
}

\author{
Francesca Maccioni and Celine D. Alt
}

\section{Learning Objectives}

- To gain a basic knowledge on anatomy and pathophysiology of the pelvic floor unit

- To get familiar with the recently published general recommendations for standardized imaging and reporting of pelvic floor disorder using MRI

- To discuss how to apply these recommendations in case-based evaluations

\section{$2.1 \quad$ Introduction}

The female pelvic floor is a complex functional and anatomic system. It is composed of an active muscular component and a passive support system. Furthermore, it is topographically divided in three main functional and anatomic compartments: the anterior, supporting the bladder and urethra; the middle, supporting the vagina and uterus; and the posterior or anorectal compartment [1]. When the pelvic floor is damaged in its fascial, muscular, or neural components at the level of any of its three compartments, several pelvic floor dysfunctions or disorders (PFD) may arise [2]. As pelvic floor muscles and fasciae act like a unique functional entity, dysfunction of one compartment is commonly associated with various dysfunctions of the other compartments as well. Hence, a multidisciplinary team, often called a pelvic floor unit, is strongly recommended that includes urogynecologists, urologists, gastroenterologists,

F. Maccioni $(\square)$

Department of Radiological Sciences, Oncology and Pathology,

Sapienza University of Rome, Rome, Italy

e-mail: francesca.maccioni@uniroma1.it

\section{D. Alt}

Department of Diagnostic and Interventional Radiology, University Duesseldorf, Medical Faculty, Duesseldorf, Germany

e-mail: celine.alt@med.uni-duesseldorf.de proctologists, physicians, radiologists, physiotherapists, and specialized nurses. Additionally, the correct diagnosis of the specific PFD and the identification of all associated disorders are mandatory for an effective conservative or surgical treatment. Dynamic MRI provides excellent morphological and functional display of the pelvic floor and is therefore additionally applied for a comprehensive overview of the pelvic floor and the entire pelvic structures. Evaluation is best done by performing a standardized MRI procedure and using a systemic approach to report the MRI findings [3]. To improve effective communication between the radiologist and the clinician, it is also relevant to understand the specific lesions underlying PFD and to explain the frequent association of disorders in different pelvic compartments.

\subsection{Functional Anatomy of the Pelvic Floor}

\subsubsection{Pathogenesis}

The pelvic floor is an integrated system composed of an active component, the striated muscles, and a passive support system, the suspensory ligaments and fascial coverings, and is associated with an intricate neural network. It not only provides support for the pelvic viscera (bladder, bowel, uterus) but maintains their functioning, thanks to the combined action of the two major pelvic floor structures: the levator ani muscle (LAM), and the endopelvic fascia $[1,2,4]$.

\subsubsection{Levator Ani Muscle (LAM)}

The LAM has two main components: the iliococcygeus and pubococcygeus muscles. Various muscle subdivisions of the LAM are assigned to the medial portions of the pubococcygeus in order to reflect the attachments of the muscle to the 
urethra, vagina, anus, and rectum. These subdivisions of the LAM are referred to as the Mm. pubourethralis, pubovaginalis, puboanalis, and puborectalis or, collectively, as the $\mathrm{M}$. pubovisceralis. More posteriorly, the pelvic diaphragm becomes continuous with the ischiococcygeus muscle. The LAM contracts continuously, providing tone to the pelvic floor against stress coming from gravity and intra-abdominal pressure. LAM contraction closes the urogenital hiatus and compresses the urethra, vagina, and anorectal junction (ARJ) in the direction of the pubic bone. Furthermore, the puborectalis component of the LAM, called the puborectal muscle, is an intrinsic and relevant part of the anal sphincter complex. It plays a primary role in the defecation process, acting as a sling that opens and closes access to the anal canal. Relaxation of the puborectal muscle, in fact, opens the anorectal angle (ARA); its contraction closes this angle, thus impeding defecation.

\subsubsection{Endopelvic Fascia}

The endopelvic fascia is a layer of connective tissue that connects and attaches the uterus and vagina to the pelvic bones [1]. Pelvic organs are supported by a series of fascial (ligamental) and elastic condensations of the endopelvic fascia, which support the uterus and vagina, preventing genital organ prolapse.

\subsubsection{Pubocervical Fascia}

The anterior portion of the endopelvic fascia, the pubocervical fascia, extends from the anterior vaginal wall to the pubis and supports the bladder. Damage to this ligament may cause urethral hypermobility and urinary incontinence.

\subsubsection{Rectovaginal Fascia}

The posterior portion of the endopelvic fascia forms the rectovaginal fascia, called Denonvilliers aponeurosis, composed of thin, connective tissue in the rectovaginal septum. It further extends, along with the cardinal and uterosacral ligaments (parametrium), from the posterior cervix and vaginal wall toward the sacrum [1]. Damage to or weakness of this fascia represents a major cause of rectocele.

\subsubsection{Etiology of Pelvic Floor Failure}

Obstetric lesions are considered primary causes of pelvic floor damage. Lesions of the iliococcygeus muscles are more frequent in the first phase of delivery, whereas the pubococcygeus muscles may be damaged in the second phase; midline episiotomy or forceps delivery are associated with anal sphincter rupture $[2,5]$. During delivery, damage to the ante- rior portion of the endopelvic fascia (pubocervical fascia) may determine urethral hypermobility and/or cystocele, whereas a lesion of its posterior portion, the rectovaginal fascia, may result in an anterior rectocele or enterocele [5]. Pudendal nerve impairment during vaginal delivery for ischemic and mechanical factors diminishes the LAM's capability for providing adequate pelvic support. Other causes of pelvic floor weakness include aging, obesity, hysterectomy, and the patient's genetic predisposition.

\subsubsection{Indication for Dynamic Pelvic Floor Imaging}

A pelvic floor disorder (PFD) is characterized by a variable association of pelvic organ prolapse (POP) and functional disturbances involving the bladder (e.g., urinary incontinence and/or voiding dysfunction), the vagina and/or uterus (e.g., sexual dysfunctions), and the rectum (e.g., obstructed defecation syndrome (ODS)) [4]. The most common PFD are ODS, POP, and urinary incontinence. Nearly $50 \%$ of multiparous women $>50$ years of age are affected by these disorders, with a negative impact on their quality of life and a frequent need of invasive surgical treatments [2, 4].

\section{Key Point}

- The pelvic floor should be considered as one unit since the three compartments work as one entity. Therefore, combined defects of the pelvic floor are common and the entire pelvis should be evaluated for PFD diagnosis.

\subsection{Diagnosis of PFD Using Dynamic MRI}

Dynamic pelvic floor (DPF)-MRI has emerged a valuable alternative technique for assessing PFD and grading POP, especially in the posterior compartment $[6,7]$. Thanks to its multiplanar capability and high soft tissue contrast, MRI allows comprehensive morphologic and functional evaluation of all three compartments at the same time, without the use of ionizing radiation. It enables real-time assessment of functional diseases with dynamic acquisitions, similar to conventional defecography [6]. The main limit of MRI is the obliged supine position for patient imaging, which is necessary if a closed 1.5-Tesla magnet is used. The supine position of MR defecography has been criticized because defecation evaluation is not under physiological conditions [8, 9]. 
Comparative studies performed with open and closed magnets have ultimately established a good concordance between results obtained in the sitting and the supine position, thus validating the use of closed MRI for assessing defecation [8]. For over 25 years, since its early clinical introduction, dynamic MRI for the evaluation of pelvic floor dysfunction has been performed with extremely heterogeneous techniques due to the variability of patient preparation, MRI equipments, and image evaluation systems [10, 11]. Recently a standardized technique for DPF-MRI performance evaluation has been proposed by a ESUR-ESGAR working group of experts [3].

\section{Key Point}

- There is no difference in the detection of clinically relevant pathologies regarding PFD when performing dynamic MRI in sitting position (open magnet) or in supine position (closed magnet).

\subsubsection{General Preparation}

According to the recommendations on MR defecography, the patient should void for about $2 \mathrm{~h}$ before the examination to have the bladder moderately filled [3]. A rectal cleansing enema the evening before the examination might be helpful but is not obligatory needed. To decrease patients' discomfort and to increase patients' compliance during dynamic and evacuation phases, a protective pad or a diaper pant should be offered to the patient. Prior to the examination, the full history of pelvic floor disorder should be taken, and the patient should be trained on how to correctly perform the dynamic phases of the examination and the evacuation phase. The patient should be informed that the full extent of pelvic organ prolapse (POP) and certain abnormalities are only visible during defecation, which makes evacuation of the gel mandatory [3].

\subsubsection{DPF-MRI Procedure}

\subsubsection{Patients' Positioning and Preparation}

The given technical aspects of MRI of the pelvic floor relate to conventional closed configuration magnets for MR imaging allowing patient positioning in lying body position only [3]. The MR defecography should preferably be performed with at least $1.5 \mathrm{~T}$ using a phased array coil centered low on the pelvis to ensure complete visualization of prolapsed organs [3]. The patient is placed in the supine position with the knees elevated (e.g., on a pillow with firm consistency) which facilitates straining and evacuation. No oral or intravenous contrast is necessary. Vaginal filling with $20 \mathrm{~cm}^{3}$ ultrasound gel is helpful for better demarcation, but its application may be limited due to social or religious backgrounds. However, the rectum should be distended with ultrasound gel, especially in order to clearly diagnose an intussusception and to evaluate the efficacy of rectal evacuation [3].

\subsubsection{MRI Sequences}

The recommended MR-defecography protocol consists of static MR sequences (high-resolution T2-weighted images (T2WI), e.g., TSE, FSE, RARE) in three planes and dynamic MR sequences (steady state, e.g., FISP, GRASS, FFE, PSIF, SSFP, and T2-FFE, or balanced-state-free precession sequence, e.g., TrueFISP, FIESTA, b-FFE) in sagittal plane (squeezing, straining, defecation). Adequate pelvic stress during the dynamic sequences is important in order to assess the full extent of pelvic floor disorder. Therefore, a clear movement of the abdominal wall and the small bowel must be seen during dynamic phases. The dynamic sequences "squeezing" and "straining" require breath holding, wherefore the duration should not exceed 20 seconds each [3]. The "defecation" sequence should be repeated until the rectum is emptied (total time duration around 2-3 min) to show full extent of POP and to exclude rectal intussusception [3].

\section{Key Point}

- Adequate pelvic stress during straining (clear movement of the abdominal wall and small bowel is seen) and the evacuation of the rectal gel during defecation are crucial so that the examination can be considered diagnostic.

\subsubsection{MRI Interpretation}

The static images should be analyzed for detection and classification of structural abnormalities, while the dynamic images should be analyzed with regard to functional abnormalities assessed by metric measurements of the three compartments of the pelvic floor. Due to the different views of the clinical specialists involved in the treatment of pelvic floor disorder, it is suggested to consider adapting the MRI reporting scheme according to the specialty of the referring physician [3].

\subsubsection{Measurement and Grading}

The pubococcygeal line (PCL) is the recommended reference line to measure POP as it practically represents the level of the pelvic floor [3]. It is drawn on sagittal plane from the inferior aspect of the pubic symphysis to the last coccy- 
geal joint [10]. After defining the PCL, the distance from each reference point is measured perpendicularly to the PCL at rest and at maximum strain.

The organ-specific reference point in the anterior, middle, and posterior compartment is the most inferior aspect of the bladder base (B), the anterior cervical lip (most distal edge of the cervix) (C), or the vaginal vault in case of previous hyster-

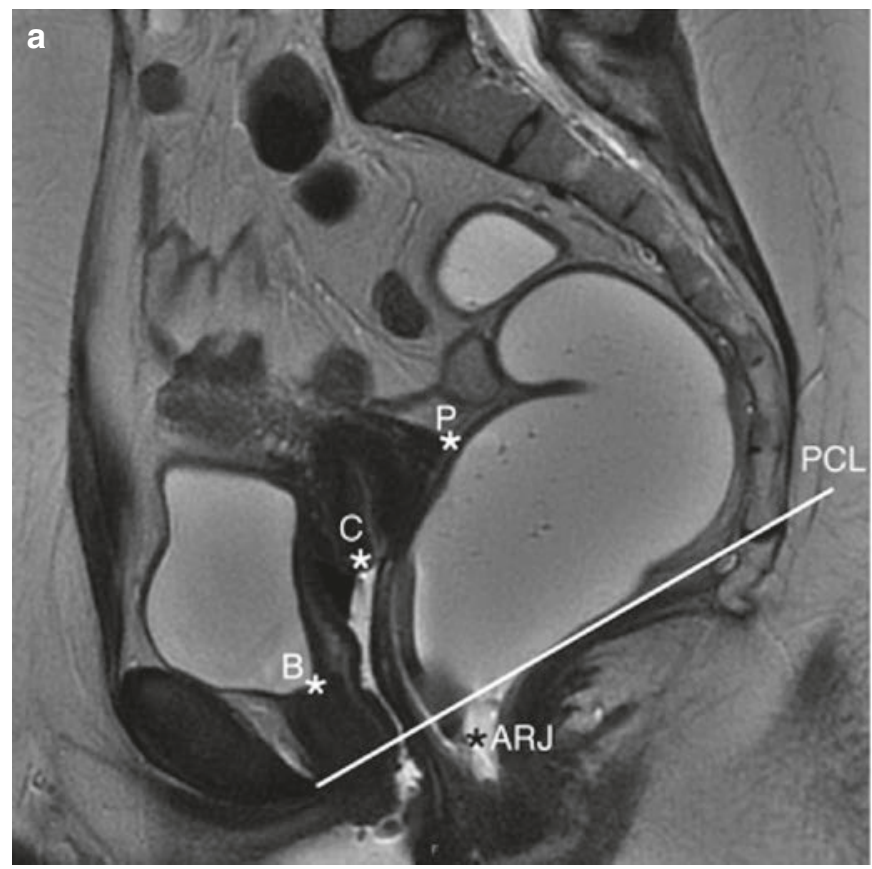

Fig. 2.1 (a, b) Presentation of the metric measurements on sagittal plane at rest. (a) The reference points are marked according to the PCL. This image at rest presents all reference points in a normal location without protrusion or descent. (b) The hiatus at rest presents with a ectomy $(\mathrm{V})$, the pouch of Douglas $(\mathrm{P})$, and the anorectal junction (ARJ) (Fig. 2.1a) [3]. Measured values above the reference line have a minus sign, values below a plus sign [12].

The anorectal angle (ARA) should be drawn along the posterior border of the rectum and a line along the central axis of the anal canal on sagittal plane at rest, squeezing and maximum straining (Fig. 2.2) [3].

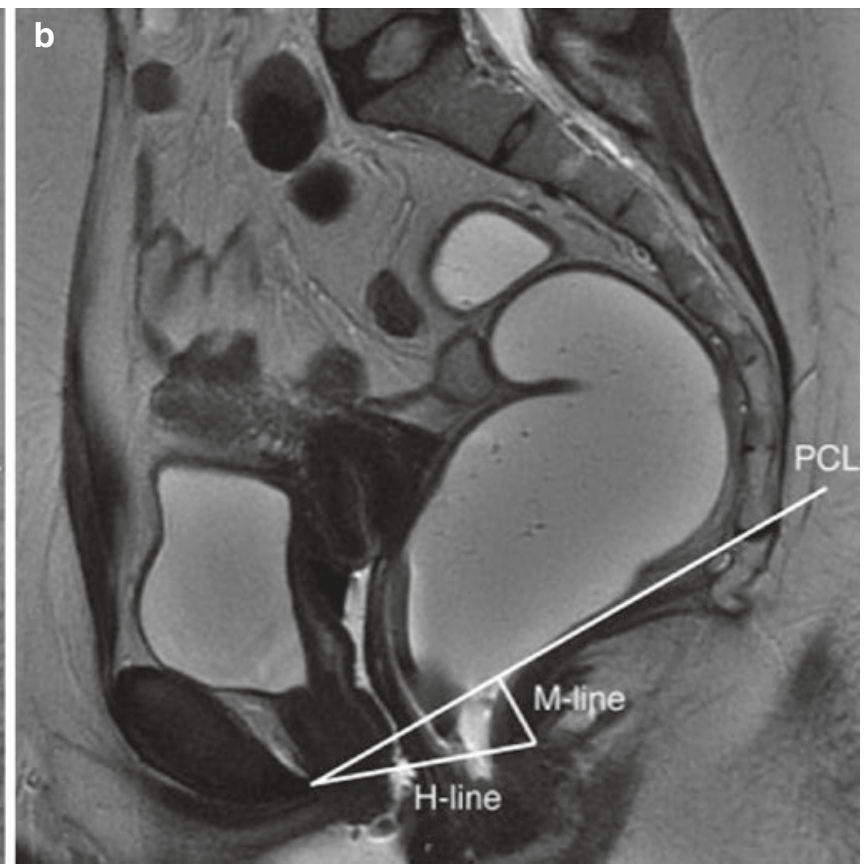

normal width and is located in a normal position according to the pelvic floor level (PCL) without descent (M-line). $P C L$ pubococcygeal line, $B$ bladder neck, $C$ anterior cervical lip, $P$ douglas pouch, $A R J$ anorectal junction, $H$-line hiatal width, $M$-line hiatal descent
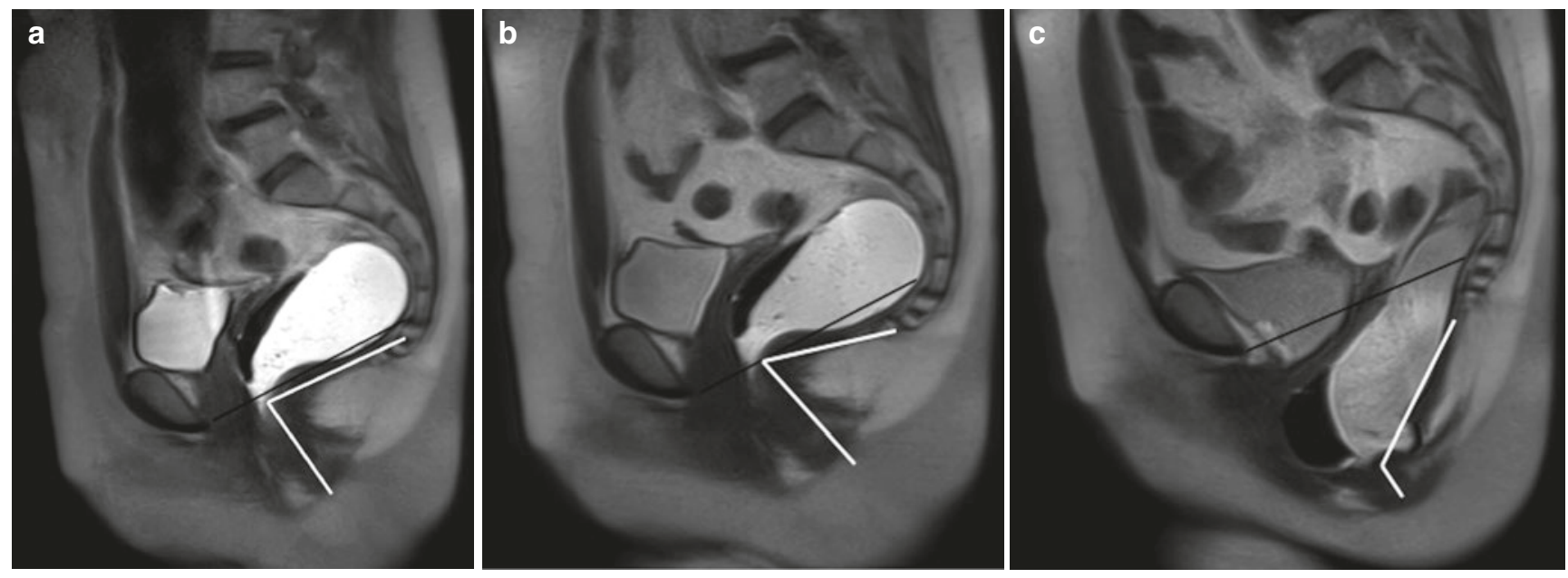

Fig. 2.2 (a-c) Anorectal angle variations. (a) Sagittal T2-weighted image at rest after rectal filling with gel. The anorectal angle (white line) is approximately $85^{\circ}$. The anorectal junction corresponds to the apex of the angle, and it is placed at the level of the PCL. (b) Sagittal T2-weighted image during squeezing of the pelvic floor. The anorectal angle (white line) is reduced to $80^{\circ}$. The anorectal junction remains at the level of the PCL. (c) Sagittal T2-weighted image during straining. The anorectal angle (white line) opens to $130^{\circ}$ due to rectal prolapse $\left(160^{\circ}\right)$ and is associated with severe prolapse of the anorectal junction $(6 \mathrm{~cm}) . P C L$ pubococcygeal line (black line) 
To grade pelvic organ prolapse in the anterior and middle compartment, the recommended grading system starts at $+1 \mathrm{~cm}$ below the PCL based on the fact that the pelvic floor may normally descend and widen up to $2 \mathrm{~cm}$ during abdominal pressure and the pelvic organs consequently follow the movement of the pelvic floor inferiorly [13]. The recommended grading system for cystoceles and uterine descent is as follows: ${ }^{\circ} 0=$ up to $+1 \mathrm{~cm}$ below the PCL, ${ }^{\circ} \mathrm{I}=+1$ to $+3 \mathrm{~cm}$ below the PCL, ${ }^{\circ} \mathrm{II}=+3$ to $+6 \mathrm{~cm}$ below the PCL, and ${ }^{\circ} \mathrm{III}=$ more than $+6 \mathrm{~cm}$ below the PCL [3].

The position of the anorectal junction is stated to be normal up to $+3 \mathrm{~cm}$ below the PCL. The recommended grading system for rectal descent is therefore as follows [14]: ${ }^{\circ} 0=$ up to $+3 \mathrm{~cm}$ below the $\mathrm{PCL},{ }^{\circ} \mathrm{I}=$ between +3 and $+5 \mathrm{~cm}$ below the PCL, and ${ }^{\circ} \mathrm{II}=$ more than $+5 \mathrm{~cm}$ below the PCL $[3,14]$.

The anterior rectal wall bulge in rectoceles should be reported as pathological from grade ${ }^{\circ} \mathrm{II}$, as a grade ${ }^{\circ} \mathrm{I}$ rectocele can be observed in nearly $78-99 \%$ of parous women, while rarely in men $[7,15,16]:{ }^{\circ} 0=$ no outpouching, ${ }^{\circ} \mathrm{I}=$ outpouching up to $2 \mathrm{~cm},{ }^{\circ} \mathrm{II}=$ outpouching between 2 and $4 \mathrm{~cm}$, and ${ }^{\circ} \mathrm{III}=$ outpouching at least $4 \mathrm{~cm}[3]$.

\subsubsection{Further Evaluation}

If a cystocele is present, the differentiation of a distention (central defect) or a displacement (lateral defect) cystocele can be made, which is relevant for therapy planning [17].

If a herniation of the pelvic peritoneal sac into the rectogenital pouch (pouch of Douglas) is present, the report should include the content of the peritoneal sac [3]. It may contain fat (called peritoneocele), small-bowel loops (properly defined as enterocele), or sigmoid colon (defined as sigmoidocele).

The change of the ARA expresses the functioning of the puborectal muscle. In healthy individuals in the supine position, the ARA at rest is between 85 and $95^{\circ}$ [6]. During squeezing pelvic organs elevate in relationship to the PCL, sharpening the ARA by $10-15^{\circ}$ (due to contraction of the puborectal muscle), while during straining and defecation, the ARA becomes more obtuse, typically by $15-25^{\circ}$, than when measured at rest (Fig. 2.2) [6].

Anismus is characterized by lack or insufficient relaxation of the puborectal muscle and external anal sphincter during defecation [6]. Anismus determines constipation and incomplete defecation due to a paradoxical contraction of the puborectal muscle during straining and defecation, without significant variation in the ARA in the different functional phases.

If no evacuation of rectal content at all or a delayed evacuation time is present although the compliance is good (more than 30 seconds to evacuate $2 / 3$ of the rectal content), anismus should be considered [3, 18].

Functional abnormalities like loss of urine through the urethra during maximum straining, urethral hypermobility, urethral funneling, or a contrary movement of the puborectal muscle should be reported if present [3].
Reporting of pelvic organ mobility (the movement of the organs compared to their location at rest) can give more valuable information than a grading system alone, taking into consideration that each woman has a unique straining of her pelvic floor and the grade of prolapse alone may not fully depict individual manifestation of POP or PFD [19].

Pelvic floor relaxation often coexists with pelvic organ prolapse. For quantification of the weakness of the levator ani and to reflect pelvic floor laxity, the length of the hiatus (H-line; extending from the inferior aspect of the pubic bone to the posterior wall of the rectum), the descent of the levator plate (M-line), and the levator plate angle can be evaluated on sagittal plane at rest and during maximal straining (Fig. 2.1b) [3]. Generalized pelvic floor weakness is also defined as descending perineal syndrome. One of the main causes is thought to be excessive anismus.

Structural defects and anatomical abnormalities like urethral ligament defect and/or distortion; puborectalis muscle detachment, disruption, atrophy, or avulsion; or diffuse or focal iliococcygeus muscle abnormality are commonly assessed on static T2-weighted images and should be reported if present [3].

\subsection{Overview on Compartment-Based Symptoms}

\subsubsection{Anterior Compartment}

Stress urinary incontinence (SUI) is the most common type of urinary incontinence in women, commonly caused by a defect in the urethral support system [20]. Other pathological causes have been attributed to urethral hypermobility, intrinsic sphincter deficiency, or urethral trauma (e.g., resulting from childbearing, surgical trauma, prolonged increased abdominal pressure) [21-23]. Women suffering from SUI often fear urinary leakage and are therefore impaired in their social or physical activities [24].

\subsubsection{Middle Compartment}

Women affected by levator ani trauma (e.g., caused by vaginal childbirth) may suffer from non-specific complaints as abnormal emptying of the bladder, frequency and urgency, organ protrusion, pelvic pain, or pressure, as well as from dyspareunia and urinary or fecal incontinence $[13,25]$. POP of the middle compartment may arise from damages of the connective tissue or vaginal supporting structures due to age or collagen defects. However, an avulsion of the pubovisceral muscle at its inferior aspect or the detachment from its 
insertion on the arcus tendineus fasciae pelvis band during vaginal delivery causes laxity and is propagated as the most common cause of pelvic floor dysfunction [26].

\subsubsection{Posterior Compartment}

The obstructed defecation syndrome (ODS) is the most frequent symptom related to the posterior compartment and may be sustained either by mechanical causes (e.g., rectal prolapse, rectal descent, rectal invagination, rectocele, enterocele) or by a functional disorder (puborectalis syndrome, dyssynergic defecation) [6,27].

Common symptoms of rectal prolapse include constipation, sensation of incomplete evacuation, fecal incontinence, and rectal ulceration with bleeding.

An intrarectal intussusception (invagination of the rectal wall) may produce a sensation of incomplete emptying, whereas an intra-anal invagination rather produces a sensation of incomplete or obstructed defecation due to outlet obstruction. High-grade intussusceptions are frequently associated with a rectocele (Figs. 2.3 and 2.4) [28, 29].

Enteroceles may be symptomatic, causing a sense of fullness and incomplete evacuation and occasionally lower abdominal pain (Fig. 2.5). However, an enterocele does not usually impair evacuation [6].

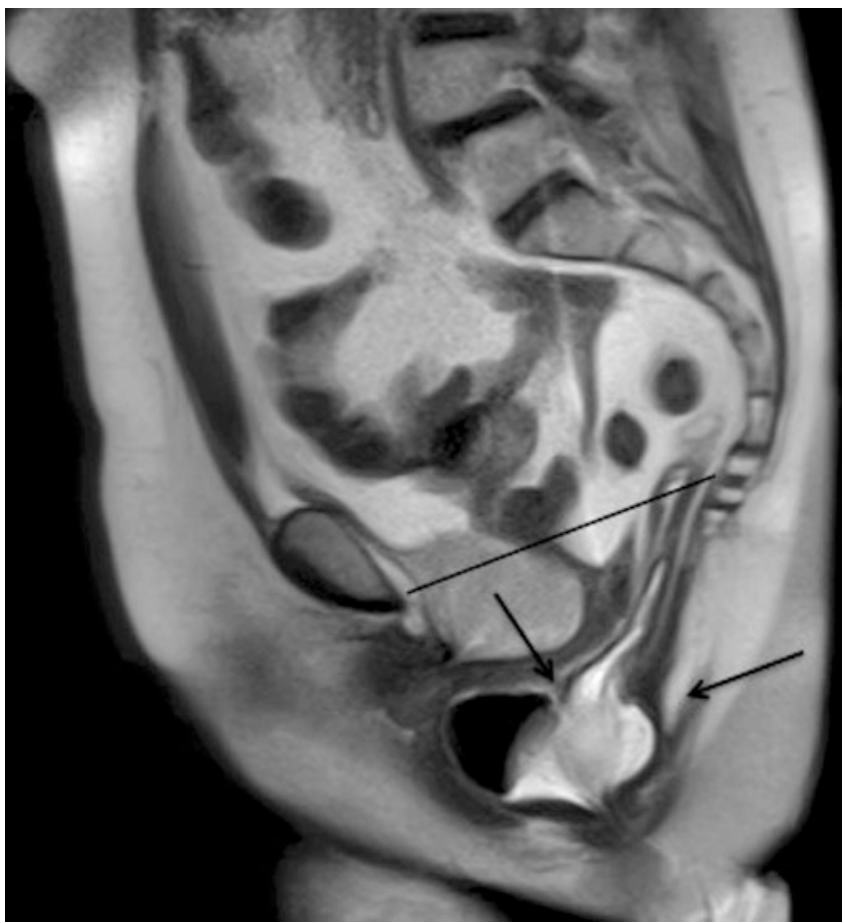

Fig. 2.3 Tricompartment prolapse in a patient with obstructed defecation syndrome. In the evacuation phase, a large anterior rectocele develops $(>4 \mathrm{~cm})$ associated with rectal invagination, severe descent of the ARJ $(>6 \mathrm{~cm})$, cystocele $(>4 \mathrm{~cm})$, and vaginal vault prolapse after hysterectomy
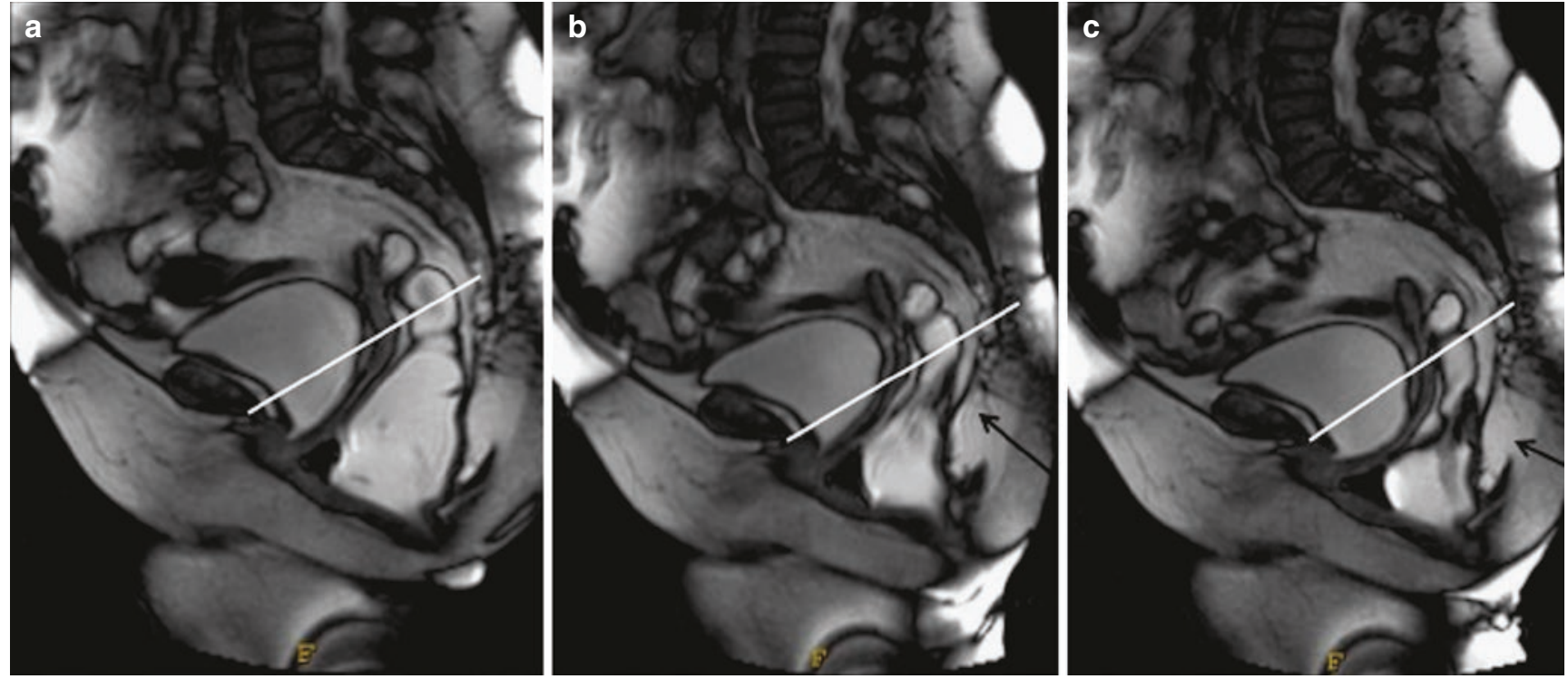

Fig. 2.4 (a-c) Rectocele with rectal invagination during progressive straining. (a) Sagittal balanced image after filling with rectal gel shows an anterior rectocele $(3 \mathrm{~cm})$ associated with prolapsed anorectal junc- tion $(5 \mathrm{~cm})$. (b) Progressive straining shows rectal invagination above the rectocele. (c) Rectal invagination and rectocele are more evident at maximum straining during evacuation 


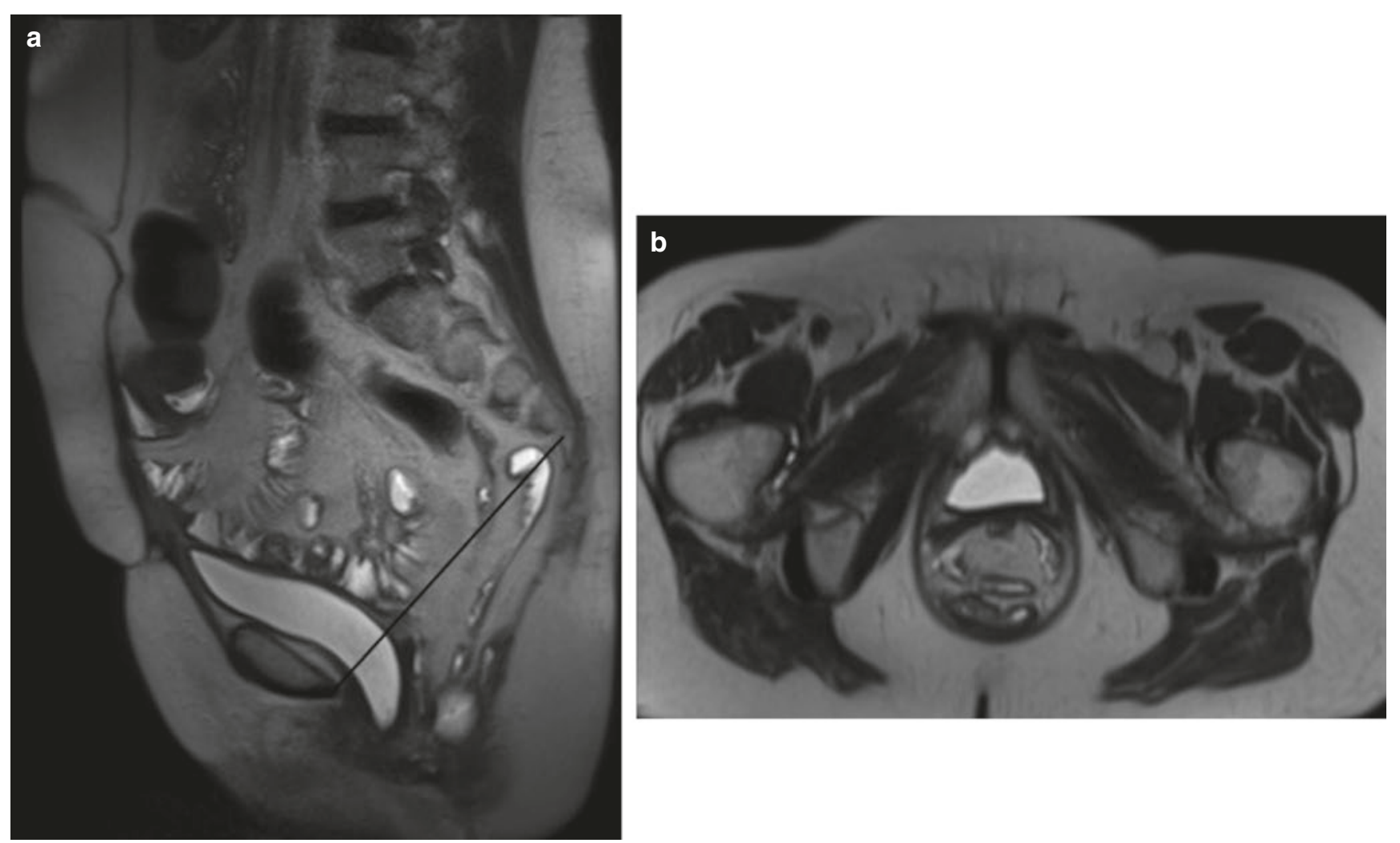

Fig. 2.5 (a, b) Tricompartment pelvic organ prolapse with cystocele, enterocele, and rectal prolapse. In the rectum, a balloon catheter is visible. (a) T2-weighted sagittal image. (b) Axial view, with clear opening

Symptoms related to a rectocele include vaginal bulging, dyspareunia, the sensation of a mass in the vagina, defecatory dysfunction, constipation, or the sensation of incomplete evacuation. The fecal trapping in the rectocele leads many patients to empty their bowels by digitating and pressing on the posterior wall of the vagina or perineum.

\section{Key Point}

- An intussusception is commonly only visible at the end of defecation phase, when the gel is evacuated; therefore it is mandatory to extend the defecation sequence in time or repeat the sequence if necessary.

\subsection{Concluding Remarks}

Dynamic pelvic floor MRI provides relevant morphological and functional information on pelvic floor structures for the diagnosis of pelvic floor disorder. However, knowledge of the pelvic hiatus and prolapse of the bladder base and small-bowel loops (cystocele and enterocele)

about anatomy and pathogenesis of the pelvic floor unit as well as information about patients' history are crucial for the interpretation of dynamic pelvic floor MRI. Additionally, a systemic approach to perform and report dynamic pelvic floor MRI is crucial to enhance effective communication between the radiologist and the clinician for the sake of patients' benefit. The recently published recommendations on MR defecography by experts of the ESUR/ESGAR should be used, and all patients should undergo the same preparation and protocol, regardless of the leading symptoms of PFD to guarantee a complete documentation of the pelvic floor.

\section{References}

1. DeLancey JO. The anatomy of the pelvic floor. Curr Opin Obstet Gynecol. 1994;6(4):313-6.

2. Olsen AL, Smith VJ, Bergstrom JO, Colling JC, Clark AL. Epidemiology of surgically managed pelvic organ prolapse and urinary incontinence. Obstet Gynecol. 1997;89(4):501-6.

3. El Sayed RF, Alt CD, Maccioni F, Meissnitzer M, Masselli G, Manganaro L, et al. Magnetic resonance imaging of pelvic floor 
dysfunction - joint recommendations of the ESUR and ESGAR Pelvic Floor Working Group. Eur Radiol. 2017;27(5):2067-85.

4. Elneil S. Complex pelvic floor failure and associated problems. Best Pract Res Clin Gastroenterol. 2009;23(4):555-73.

5. Mortele KJ, Fairhurst J. Dynamic MR defecography of the posterior compartment: Indications, techniques and MRI features. Eur J Radiol. 2007;61(3):462-72.

6. Maccioni F. Functional disorders of the ano-rectal compartment of the pelvic floor: clinical and diagnostic value of dynamic MRI. Abdom Imaging. 2013;38(5):930-51.

7. Elshazly WG, El Nekady Ael A, Hassan H. Role of dynamic magnetic resonance imaging in management of obstructed defecation case series. Int J Surg. 2010;8(4):274-82.

8. Bertschinger KM, Hetzer FH, Roos JE, Treiber K, Marincek B, Hilfiker PR. Dynamic MR imaging of the pelvic floor performed with patient sitting in an open-magnet unit versus with patient supine in a closed-magnet unit. Radiology. 2002;223:501-8.

9. Roos JE, Weishaupt D, Wildermuth S, Willmann JK, Marincek B, Hilfiker PR. Experience of 4 years with open MR defecography: pictorial review of anorectal anatomy and disease. Radiographics. 2002;22(4):817-32.

10. Yang A, Mostwin JL, Rosenshein NB, Zerhouni EA. Pelvic floor descent in women: dynamic evaluation with fast MR imaging and cinematic display. Radiology. 1991;179(1):25-33.

11. Maccioni F, Al Ansari N, Buonocore V, et al. Prospective comparison between two different magnetic resonance defecography techniques for evaluating pelvic floor disorders: air-balloon versus gel for rectal filling. Eur Radiol. 2016;26(6):1783-91.

12. Singh K, Jakab M, Reid WM, Berger LA, Hoyte L. Threedimensional magnetic resonance imaging assessment of levator ani morphologic features in different grades of prolapse. Am J Obstet Gynecol. 2003;188(4):910-5.

13. Boyadzhyan L, Raman SS, Raz S. Role of static and dynamic MR imaging in surgical pelvic floor dysfunction. Radiographics. 2008;28(4):949-67.

14. Halligan S, Bartram C, Hall C, Wingate J. Enterocele revealed by simultaneous evacuation proctography and peritoneography: Does "defecation block" exist? Am J Roentgenol. 1996;167(2):461-6.

15. Morren GL, Balasingam AG, Wells JE, Hunter AM, Coates RH, Perry RE. Triphasic MRI of pelvic organ descent: sources of measurement error. Eur J Radiol. 2005;54(2):276-83.

16. Woodfield CA, Hampton BS, Sung V, Brody JM. Magnetic resonance imaging of pelvic organ prolapse: comparing pubococcygeal and midpubic lines with clinical staging. Int Urogynecol J Pelvic Floor Dysfunct. 2009;20(6):695-701.

17. Elsayed RF. Anterior compartment. In: Shaaban AM, editor. Diagnostic imaging: gynecology. 2nd ed. Amirsys: Elsevier; 2015. p. 8-40-68.

18. Halligan S, Bartram CI, Park HJ, Kamm MA. Proctographic features of anismus. Radiology. 1995;197(3):679-82.

19. Alt CD, Brocker KA, Lenz F, Sohn C, Kauczor HU, Hallscheidt P. MRI findings before and after prolapse surgery. Acta Radiol. 2014;55(4):495-504.

20. Deutchman M, Wulster-Radcliffe M. Stress urinary incontinence in women: diagnosis and medical management. MedGenMed. 2005;7(4):62.

21. Koelbl H, Mowstin J, Boiteux JP. Pathophysiology. In: Abrams P, Cardozo L, Koury S, Wein A, editors. Incontinence. Plymouth: Health Publications Ltd.; 2002. p. 165-201.

22. Kim JK, Kim YJ, Choo MS, Cho KS. The urethra and its supporting structures in women with stress urinary incontinence: MR imaging using an endovaginal coil. AJR Am J Roentgenol. 2003;180(4):1037-44.

23. Mostwin JL, Yang A, Sanders R, Genadry R. Radiography, sonography, and magnetic resonance imaging for stress incontinence. Contributions, uses, and limitations. Urol Clin North Am. 1995;22(3):539-49.

24. Abrams P, Cardozo L, Fall M, Griffiths D, Rosier P, Ulmsten U, et al. The standardisation of terminology of lower urinary tract function: report from the Standardisation Sub-committee of the International Continence Society. NeurourolUrodyn. 2002;21(2):167-78.

25. Petros P. The female pelvic floor: function, dysfunction, and management according to the integral theory. 2nd ed. Heidelberg: Springer; 2007. p. xix. 260 p

26. DeLancey JO, Kearney R, Chou Q, Speights S, Binno S. The appearance of levator ani muscle abnormalities in magnetic resonance images after vaginal delivery. Obstet Gynecol. 2003;101(1):46-53.

27. Zbar AP. Posterior pelvic floor disorders and obstructed defecation syndrome: clinical and therapeutic approach. Abdom Imaging. 2013;38(5):894-902.

28. Felt-Bersma RJ, Cuesta MA. Rectal prolapse, rectal intussusception, rectocele, and solitary rectal ulcer syndrome. Gastroenterol Clin North Am. 2001;30(1):199-222.

29. Kenton K, Shott S, Brubaker L. The anatomic and functional variability of rectoceles in women. Int Urogynecol J Pelvic Floor Dysfunct. 1999;10(2):96-9.

Open Access This chapter is licensed under the terms of the Creative Commons Attribution 4.0 International License (http://creativecommons. org/licenses/by/4.0/), which permits use, sharing, adaptation, distribution and reproduction in any medium or format, as long as you give appropriate credit to the original author(s) and the source, provide a link to the Creative Commons license and indicate if changes were made.

The images or other third party material in this book are included in the book's Creative Commons license, unless indicated otherwise in a credit line to the material. If material is not included in the book's Creative Commons license and your intended use is not permitted by statutory regulation or exceeds the permitted use, you will need to obtain permission directly from the copyright holder. 